\title{
VARIANTS OF $R$-WEAKLY COMMUTING MAPPINGS SATISFYING A WEAK CONTRACTION
}

\author{
DEEPAK JAIN, SANJAY KUMAR, AND CHOONKIL PARK
}

Received 08 September, 2019

\begin{abstract}
In this paper, first we prove a common fixed point theorem for pairs of weakly compatible mappings satisfying a generalized $\phi$-weak contraction condition that involves cubic terms of metric functions. Secondly, we prove some results using different variants of $R$-weakly commuting mappings. At the end, we give an application in support of our results.
\end{abstract}

2010 Mathematics Subject Classification: 47H10; 54H25; 68U10

Keywords: $\phi$-weak contraction, variant of $R$-weakly commuting mappings, common fixed point, sequence of mappings, compatible mapping

\section{INTRODUCTION AND PRELIMINARIES}

The Banach Contraction Principle is a basic tool to study fixed point theory, which ensures the existence and uniqueness of a fixed point under appropriate conditions. It is most widely applied to understand fixed point results in many branches of mathematics because it requires the structure of complete metric spaces. Generalizations of Banach Contraction Principle gave new direction to researchers in the field of fixed point theory. In 1969, Boyd and Wong [4] replaced the constant $k$ in Banach Contraction Principle by a control function $\psi$ as follows:

Let $(X, d)$ be a complete metric space and $\psi:[0, \infty) \rightarrow[0, \infty)$ be an upper semi continuous from the right such that $0 \leq \psi(t)<t$ for all $t>0$. If $T: X \rightarrow X$ satisfies $d(T(x), T(y)) \leq \psi(d(x, y))$ for all $x, y \in X$, then it has a unique fixed point.

In 1994, Pant [13] introduced the notion of $R$-weakly commuting mappings in metric spaces. In 1997, Pathak et al. [14] improved the notion of $R$-weakly commuting mappings to the notion of $R$-weakly commuting mappings of type $\left(A_{g}\right)$ and $R$-weakly commuting mappings of type $\left(A_{f}\right)$. In fact, the main application of $R$ weakly commuting mappings of type $\left(A_{f}\right)$ or type $\left(A_{g}\right)$ is to study common fixed

The first author was supported in part by the Council of Scientific and Industrial Research, New Delhi for providing the fellowship vide file No. 09/1063/0009/2015-EMR-1 (JRF/SRF).

The third author was supported in part by Basic Science Research Program through the National Research Foundation of Korea funded by the Ministry of Education, Science and Technology (NRF2017R1D1A1B04032937). 
points for noncompatible mappings. In 1998, Jungck and Rhoades [9] introduced the notion of weakly compatible mappings. In 2006, Imdad and Ali [5] introduced $R$-weakly commuting mappings of type $(P)$ in fuzzy metric spaces. In 2009, Kumar and Garg [12] introduced the concept of $R$-weakly commuting mappings of type $(P)$ in metric spaces analogue to the notion in fuzzy metric spaces given in [5]. In 1997, Alber and Guerre-Delabriere [2] introduced the concept of a weak contraction and further Rhoades [15] showed that the results of Alber and Gueree-Delabriere are also valid in complete metric spaces. A mapping $T: X \rightarrow X$ is said to be a weak contraction if for all $x, y \in X$, there exists a function $\phi:[0, \infty) \rightarrow[0, \infty)$ with $\phi(t)>0$ and $\phi(0)=0$ such that

$$
d(T x, T y) \leq d(x, y)-\phi(d(x, y)) .
$$

In 2017, Jain et al. [6] introduced a new type of inequality having cubic terms of $d(x, y)$ that extended and generalized the results of Alber and Gueree-Delabriere [2] and others cited in the literature of fixed point theory. See [1,3,7,10,11] for more information on fixed point theory.

In this paper, we extend and generalize the result of Jain et al. [6] for two pairs of $R$-weakly commuting mappings and its variants satisfying the generalized $\phi$-weak contractive condition involving various combinations of the metric functions.

Our improvement in this paper is four-fold:

(i) to relax the continuity requirement of mappings completely;

(ii) to derogate the commutativity requirement of mappings to the point of coincidence;

(iii) to soften the completeness requirement of the space;

(iv) to engage a more general contraction condition in proving our results.

\section{BASIC PROPERTIES}

In this section, we give some basic definitions and results that are useful for proving our main results.

Definition 1 ([8]). Two self-mappings $f$ and $g$ of a metric space $(X, d)$ are said to be commuting if $f g x=g f x$ for all $x \in X$.

The notion of weak commutativity as an improvement over the notion of commutativity was introduced by Sessa [16] in 1982 as a sharpener tool to obtain fixed point.

Definition 2 ([16]). Two self-mappings $f$ and $g$ of a metric space $(X, d)$ are said to be weakly commuting if $d(f g x, g f x) \leq d(g x, f x)$ for all $x \in X$.

Remark 1. Commutative mappings must be weak commutative mappings, but the converse is not true.

Definition 3 ([9]). Two self-mappings $f$ and $g$ of a metric space $(X, d)$ are called weakly compatible if they commute at their coincidence point. 
Definition 4 ([13]). Two self-mappings $f$ and $g$ of a metric space $(X, d)$ are said to be $R$-weakly commuting if there exists some $R \geq 0$ such that $d(f g x, g f x) \leq R d(f x, g x)$ for all $x \in X$.

Remark 2. Notice that weak commutativity of a pair of self-mappings implies $R$ weak commutativity and the converse is true only when $R \leq 1$.

Example 1. Let $X=[1, \infty)$ be endowed with the usual metric. Define $f, g: X \rightarrow X$ by $f(x)=2 x-1$ and $g(x)=x^{2}$ for all $x \in X$. Then $d(f g x, g f x)=2 d(f x, g x)$. Thus $f$ and $g$ are $R$-weakly commuting $(R=2)$ but are not weakly commuting.

Definition 5 ([14]). Two self-mappings $f$ and $g$ of a metric space $(X, d)$ are said to be $R$-weakly commuting of type $\left(A_{f}\right)$ if there exists a positive real number $R$ such that $d(f g x, g g x) \leq R d(f x, g x)$ for all $x \in X$.

Definition 6 ([14]). Two self-mappings $f$ and $g$ of a metric space $(X, d)$ are said to be $R$-weakly commuting of type $\left(A_{g}\right)$ if there exists a positive real number $R$ such that $d(g f x, f f x) \leq R d(f x, g x)$ for all $x \in X$.

It may be observed that Definition 6 can be obtained from Definition 5 by interchanging the role of $f$ and $g$. Further, $R$-weakly commuting pair of self-mappings is independent of $R$-weakly commuting of type $\left(A_{f}\right)$ or type $\left(A_{g}\right)$. In Example 1 , we note that $d(f g x, g g x)>R d(f x, g x)$ for all $x>1$ and some $R>0$. Thus $f$ and $g$ are $R$-weakly commuting but not $R$-weakly commuting of type $\left(A_{f}\right)$.

Definition 7 ([5,12]). Two self-mappings $f$ and $g$ of a metric space $(X, d)$ are said to be $R$-weakly commuting mapping of type $(P)$ if there exists some $R>0$ such that $d(f f x, g g x) \leq R d(f x, g x)$ for all $x \in X$.

Remark 3. If $f$ and $g$ are $R$-weakly commuting or $R$-weakly commuting $\left(A_{f}\right)$ or $R$ weakly commuting of type $\left(A_{g}\right)$ or $R$-weakly commuting $(P)$ and if $z$ is a coincidence point, i.e., $f z=g z$, then we get $f f z=f g z=g f z=g g z$. Thus at a coincidence point, all the analogous notions of $R$-weak commutativity including $R$-weak commutativity are equivalent to each other and imply their commutativity.

\section{MAin RESUlts}

Let $S, T, A$ and $B$ be four self-mappings of a metric space $(X, d)$ satisfying the following conditions:

(C1) $S(X) \subset B(X), \quad T(X) \subset A(X)$;

(C2) $(1+p d(A x, B y)) d(S x, T y)^{2}$

$$
\begin{aligned}
\leq & p \cdot \max \left\{\frac{1}{2}\left(d(A x, S x)^{2} d(B y, T y)+d(A x, S x) d(B y, T y)^{2}\right),\right. \\
& d(A x, S x) d(A x, T y) d(B y, S x), d(A x, T y) d(B y, S x) d(B y, T y)\} \\
+ & m(A x, B y)-\phi(m(A x, B y))
\end{aligned}
$$


for all $x, y \in X$, where

$$
\begin{gathered}
m(A x, B y)=\max \left\{d(A x, B y)^{2}, d(A x, S x) d(B y, T y), d(A x, T y) d(B y, S x),\right. \\
\left.\frac{1}{2}[d(A x, S x) d(A x, T y)+d(B y, S x) d(B y, T y)]\right\},
\end{gathered}
$$

$p \geq 0$ is a real number and $\phi:[0, \infty) \rightarrow[0, \infty)$ is a continuous function such that $\phi(t)=0$ if and only if $t=0$ and $\phi(t)>t$ for all $t>0$.

From (C1), for any arbitrary point $x_{0} \in X$, we can find an $x_{1}$ such that $S\left(x_{0}\right)=B\left(x_{1}\right)=$ $y_{0}$ and for this $x_{1}$ one can find an $x_{2} \in X$ such that $T\left(x_{1}\right)=A\left(x_{2}\right)=y_{1}$. Continuing in this way one can construct a sequence $\left\{y_{n}\right\}$ such that

$$
y_{2 n}=S\left(x_{2 n}\right)=B\left(x_{2 n+1}\right), \quad y_{2 n+1}=T\left(x_{2 n+1}\right)=A\left(x_{2 n+2}\right)
$$

for each $n \geq 0$.

Lemma 1 ([6]). Let $S, T, A$ and $B$ be four self-mappings of a metric space $(X, d)$ satisfying the conditions $(C 1)$ and (C2). Then the sequence $\left\{y_{n}\right\}$ defined by (3.1) is a Cauchy sequence in $X$.

For the convenience of the reader, we give the following proof of Lemma 1.

Proof. For brevity, we write $\alpha_{2 n}=d\left(y_{2 n}, y_{2 n+1}\right)$.

First, we prove that $\left\{\alpha_{2 n}\right\}$ is a nonincreasing sequence and converges to zero.

Case I: Suppose that $n$ is even. Taking $x=x_{2 n}$ and $y=x_{2 n+1}$ in (C2), we get

$$
\begin{aligned}
& {\left[1+p d\left(A x_{2 n}, B x_{2 n+1}\right)\right] d\left(S x_{2 n}, T x_{2 n+1}\right)^{2}} \\
& \leq p \cdot \max \left\{\frac{1}{2}\left(d\left(A x_{2 n}, S x_{2 n}\right)^{2} d\left(B x_{2 n+1}, T x_{2 n+1}\right)+d\left(A x_{2 n}, S x_{2 n}\right) d\left(B x_{2 n+1}, T x_{2 n+1}\right)^{2}\right),\right. \\
& \quad d\left(A x_{2 n}, S x_{2 n}\right) d\left(A x_{2 n}, T x_{2 n+1}\right) d\left(B x_{2 n+1}, S x_{2 n}\right), \\
& \left.\quad d\left(A x_{2 n}, T x_{2 n+1}\right) d\left(B x_{2 n+1}, S x_{2 n}\right) d\left(B x_{2 n+1}, T x_{2 n+1}\right)\right\} \\
& \quad+m\left(A x_{2 n}, B x_{2 n+1}\right)-\phi\left(m\left(A x_{2 n}, B x_{2 n+1}\right)\right),
\end{aligned}
$$

where

$$
\begin{aligned}
& m\left(A x_{2 n}, B x_{2 n+1}\right) \\
& =\max \left\{d\left(A x_{2 n}, B x_{2 n+1}\right)^{2}, d\left(A x_{2 n}, S x_{2 n}\right) d\left(B x_{2 n+1}, T x_{2 n+1}\right), d\left(A x_{2 n}, T x_{2 n+1}\right) d\left(B x_{2 n+1}, S x_{2 n}\right),\right. \\
& \left.\quad \quad \frac{1}{2}\left(d\left(A x_{2 n}, S x_{2 n}\right) d\left(A x_{2 n}, T x_{2 n+1}\right)+d\left(B x_{2 n+1}, S x_{2 n}\right) d\left(B x_{2 n+1}, T x_{2 n+1}\right)\right)\right\} . \\
& \text { Using } \alpha_{2 n}=d\left(y_{2 n}, y_{2 n+1}\right) \text { in (3.1), we have } \\
& \quad\left[1+p \alpha_{2 n-1}\right] \alpha_{2 n}^{2} \\
& \left.\quad \leq p \max \left\{\frac{1}{2}\left[\alpha_{2 n-1}^{2} \alpha_{2 n}+\alpha_{2 n-1} \alpha_{2 n}^{2}\right], 0,0\right)\right\}+m\left(y_{2 n-1}, y_{2 n}\right)-\phi\left(m\left(y_{2 n-1}, y_{2 n}\right)\right),
\end{aligned}
$$


where

$$
\left.m\left(y_{2 n-1}, y_{2 n}\right)=\max \left\{\alpha_{2 n-1}^{2}, \alpha_{2 n-1} \alpha_{2 n}, 0, \frac{1}{2}\left[\alpha_{2 n-1} d\left(y_{2 n-1}, y_{2 n+1}\right)+0\right]\right)\right\} .
$$

By the triangular inequality, we get

$$
\begin{gathered}
d\left(y_{2 n-1}, y_{2 n+1}\right) \leq d\left(y_{2 n-1}, y_{2 n}\right)+d\left(y_{2 n}, y_{2 n+1}\right)=\alpha_{2 n-1}+\alpha_{2 n}, \\
m\left(y_{2 n-1}, y_{2 n}\right) \leq \max \left\{\alpha_{2 n-1}^{2}, \alpha_{2 n-1} \alpha_{2 n}, 0, \frac{1}{2}\left[\alpha_{2 n-1}\left(\alpha_{2 n-1}+\alpha_{2 n}\right), 0\right]\right\} .
\end{gathered}
$$

If $\alpha_{2 n-1}<\alpha_{2 n}$, then (3.2) reduces to $p \alpha_{2 n}^{2} \leq p \alpha_{2 n}^{2}-\phi\left(\alpha_{2 n}^{2}\right)$, which is a contradiction. Thus $\alpha_{2 n} \leq \alpha_{2 n-1}$.

In a similar way, if $n$ is odd, then we can obtain $\alpha_{2 n+1} \leq \alpha_{2 n}$. It follows that the sequence $\left\{\alpha_{2 n}\right\}$ is decreasing.

Let $\lim _{n \rightarrow \infty} \alpha_{2 n}=r$ for some $r \geq 0$. Then from the inequality (C2), we have

$$
\begin{aligned}
& {\left[1+p d\left(A x_{2 n}, B x_{2 n+1}\right)\right] d\left(S x_{2 n}, T x_{2 n+1}\right)^{2}} \\
& \leq p \cdot \max \left\{\frac{1}{2}\left(d\left(A x_{2 n}, S x_{2 n}\right)^{2} d\left(B x_{2 n+1}, T x_{2 n+1}\right)+d\left(A x_{2 n}, S x_{2 n}\right) d\left(B x_{2 n+1}, T x_{2 n+1}\right)^{2}\right),\right. \\
& \quad d\left(A x_{2 n}, S x_{2 n}\right) d\left(A x_{2 n}, T x_{2 n+1}\right) d\left(B x_{2 n+1}, S x_{2 n}\right), \\
& \left.\quad d\left(A x_{2 n}, T x_{2 n+1}\right) d\left(B x_{2 n+1}, S x_{2 n}\right) d\left(B x_{2 n+1}, T x_{2 n+1}\right)\right\} \\
& +m\left(A x_{2 n}, B x_{2 n+1}\right)-\phi\left(m\left(A x_{2 n}, B x_{2 n+1}\right)\right),
\end{aligned}
$$

where

$$
\begin{aligned}
& m\left(A x_{2 n}, B x_{2 n+1}\right) \\
& =\max \left\{d\left(A x_{2 n}, B x_{2 n+1}\right)^{2}, d\left(A x_{2 n}, S x_{2 n}\right) d\left(B x_{2 n+1}, T x_{2 n+1}\right), d\left(A x_{2 n}, T x_{2 n+1}\right) d\left(B x_{2 n+1}, S x_{2 n}\right),\right. \\
& \left.\quad \frac{1}{2}\left(d\left(A x_{2 n}, S x_{2 n}\right) d\left(A x_{2 n}, T x_{2 n+1}\right)+d\left(B x_{2 n+1}, S x_{2 n}\right) d\left(B x_{2 n+1}, T x_{2 n+1}\right)\right)\right\} .
\end{aligned}
$$

Now using (3.2), the property of $\phi$ and passing to the limit as $n \rightarrow \infty$, we get

$$
[1+p r] r^{2} \leq p r^{3}+r^{2}-\phi\left(r^{2}\right) .
$$

So $\phi\left(r^{2}\right) \leq 0$. Since $r$ is positive, by the property of $\phi$, we get $r=0$. Therefore, we conclude that

$$
\lim _{n \rightarrow \infty} \alpha_{2 n}=\lim _{n \rightarrow \infty} d\left(y_{2 n}, y_{2 n-1}\right)=r=0 .
$$

Now we show that $\left\{y_{n}\right\}$ is a Cauchy sequence. Assume that $\left\{y_{n}\right\}$ is not a Cauchy sequence. For given $\varepsilon>0$, we can find two sequences of positive integers $\{m(k)\}$ and $\{n(k)\}$ such that for all positive integers $k, n(k)>m(k)>k$

$$
d\left(y_{m(k)}, y_{n(k)}\right) \geq \varepsilon, \quad d\left(y_{m(k)}, y_{n(k)-1}\right)<\varepsilon .
$$

Thus $\varepsilon \leq d\left(y_{m(k)}, y_{n(k)}\right) \leq d\left(y_{m(k)}, y_{n(k)-1}\right)+d\left(y_{n(k)-1}, y_{n(k)}\right)$. Taking the limit as $k \rightarrow \infty$, we get $\lim _{k \rightarrow \infty} d\left(y_{m(k)}, y_{n(k)}\right)=\varepsilon$. 
Now using the triangular inequality, we have

$$
\left|d\left(y_{n(k)}, y_{m(k)+1}\right)-d\left(y_{m(k)}, y_{n(k)}\right)\right| \leq d\left(y_{m(k)}, y_{m(k)+1}\right) .
$$

Taking the limit as $k \rightarrow \infty$ and using (3.3) and (3.4), we have

$$
\lim _{k \rightarrow \infty} d\left(y_{n(k)}, y_{m(k)+1}\right)=\varepsilon
$$

Again from the triangular inequality, we have

$$
\left|d\left(y_{m(k)}, y_{n(k)+1}\right)-d\left(y_{m(k)}, y_{n(k)}\right)\right| \leq d\left(y_{n(k)}, y_{n(k)+1}\right) .
$$

Taking the limit as $k \rightarrow \infty$ and using (3.3) and (3.4), we have

$$
\lim _{k \rightarrow \infty} d\left(y_{m(k)}, y_{n(k)+1}\right)=\varepsilon \text {. }
$$

Similarly, we have

$$
\left|d\left(y_{m(k)+1}, y_{n(k)+1}\right)-d\left(y_{m(k)}, y_{n(k)}\right)\right| \leq d\left(y_{m(k)}, y_{m(k)+1}\right)+d\left(y_{n(k)}, y_{n(k)+1}\right) .
$$

Taking the limit as $k \rightarrow \infty$ in the above inequality and using (3.3) and (3.4), we have

$$
\lim _{k \rightarrow \infty} d\left(y_{n(k)+1}, y_{m(k)+1}\right)=\varepsilon .
$$

Putting $x=x_{m(k)}$ and $y=x_{n(k)}$ in (C2), we get

$$
\begin{aligned}
& {\left[1+p d\left(A x_{m(k)}, B x_{n(k)}\right)\right] d\left(S x_{m(k)}, T x_{n(k)}\right)^{2}} \\
& \begin{array}{l}
\leq p \cdot \max \left\{\frac{1}{2}\left(d\left(A x_{m(k)}, S x_{m(k)}\right)^{2} d\left(B x_{n(k)}, T x_{n(k)}\right)+d\left(A x_{m(k)}, S x_{m(k)}\right) d\left(B x_{n(k)}, T x_{n(k)}\right)^{2}\right),\right. \\
\quad d\left(A x_{m(k)}, S x_{m(k)}\right) d\left(A x_{m(k)}, T x_{n(k)}\right) d\left(B x_{n(k)}, S x_{m(k)}\right), \\
\left.\quad d\left(A x_{m(k)}, T x_{n(k)}\right) d\left(B x_{n(k)}, S x_{m(k)}\right) d\left(B x_{n(k)}, T x_{n(k)}\right)\right\} \\
\quad+m\left(A x_{m(k)}, B x_{n(k)}\right)-\phi\left(m\left(A x_{m(k)}, B x_{n(k)}\right)\right),
\end{array}
\end{aligned}
$$

where

$$
\begin{aligned}
m\left(A x_{m(k)}, B x_{n(k)}\right)=\max \{ & d\left(A x_{m(k)}, B x_{n(k)}\right)^{2}, d\left(A x_{m(k)}, S x_{m(k)}\right) d\left(B x_{n(k)}, T x_{n(k)}\right), \\
& d\left(A x_{m(k)}, T x_{n(k)}\right) d\left(B x_{n(k)}, S x_{m(k)}\right), \\
& \frac{1}{2}\left(d\left(A x_{m(k)}, S x_{m(k)}\right) d\left(A x_{m(k)}, T x_{n(k)}\right)\right. \\
& \left.\left.+d\left(B x_{n(k)}, S x_{m(k)}\right) d\left(B x_{n(k)}, T x_{n(k)}\right)\right)\right\} .
\end{aligned}
$$

Using (3.1), we obtain

$$
\begin{aligned}
& {\left[1+p d\left(y_{m(k)-1}, y_{n(k)-1}\right)\right] d\left(y_{m(k)}, y_{n(k)}\right)^{2}} \\
& \leq p \cdot \max \left\{\frac{1}{2}\left(d\left(y_{m(k)-1}, y_{m(k)}\right)^{2} d\left(y_{n(k)-1}, y_{n(k)}\right)+d\left(y_{m(k)-1}, y_{m(k)}\right) d\left(y_{n(k)-1}, y_{n(k)}\right)^{2}\right),\right. \\
& d\left(y_{m(k)-1}, y_{m(k)}\right) d\left(y_{m(k)-1}, y_{n(k)}\right) d\left(y_{n(k)-1}, y_{m(k)}\right), \\
& \left.d\left(y_{m(k)-1}, y_{n(k)}\right) d\left(y_{n(k)-1}, y_{m(k)}\right) d\left(y_{n(k)-1}, y_{n(k)}\right)\right\} \\
& +m\left(A x_{m(k)}, B x_{n(k)}\right)-\phi\left(m\left(A x_{m(k)}, B x_{n(k)}\right)\right) \text {, }
\end{aligned}
$$


where

$$
\begin{aligned}
m\left(A x_{m(k)}, B x_{n(k)}\right)=\max \{ & d\left(y_{m(k)-1}, y_{n(k)-1}\right)^{2}, d\left(y_{m(k)-1}, y_{m(k)}\right) d\left(y_{n(k)-1}, y_{n(k)}\right), \\
& d\left(y_{m(k)-1}, y_{n(k)}\right) d\left(y_{n(k)-1}, y_{m(k)}\right), \\
& \frac{1}{2}\left(d\left(y_{m(k)-1}, y_{m(k)}\right) d\left(y_{m(k)-1}, y_{n(k)}\right)\right. \\
& \left.\left.+d\left(y_{n(k)-1}, y_{m(k)}\right) d\left(y_{n(k)-1}, y_{n(k)}\right)\right)\right\} .
\end{aligned}
$$

Taking the limit as $k \rightarrow \infty$, we get

$$
[1+p \varepsilon] \varepsilon^{2} \leq p \max \left\{\frac{1}{2}[0+0], 0,0\right\}+\varepsilon^{2}-\phi\left(\varepsilon^{2}\right)=\varepsilon^{2}-\phi\left(\varepsilon^{2}\right),
$$

which is a contradiction. Thus $\left\{y_{n}\right\}$ is a Cauchy sequence in $X$.

Now we prove our main results as follows:

Theorem 1. Let $S, T, A$ and $B$ be four self-mappings of a metric space $(X, d)$ satisfying the conditions $(C 1)$ and $(C 2)$ and one of the subspaces $A X, B X, S X$ and $T X$ be complete. Then

(i) A and $S$ have a point of coincidence;

(ii) $B$ and $T$ have a point of coincidence.

Moreover, if the pairs $(A, S)$ and $(B, T)$ are weakly compatible, then $S, T, A$ and $B$ have a unique common fixed point.

Proof. Let $x_{0} \in X$ be an arbitrary point. From (C1), we can find an $x_{1}$ such that $S\left(x_{0}\right)=B\left(x_{1}\right)=y_{0}$ and for this $x_{1}$ one can find an $x_{2} \in X$ such that $T\left(x_{1}\right)=A\left(x_{2}\right)=y_{1}$. Continuing in this way, one can construct a sequence such that

$$
y_{2 n}=S\left(x_{2 n}\right)=B\left(x_{2 n+1}\right), \quad y_{2 n+1}=T\left(x_{2 n+1}\right)=A\left(x_{2 n+2}\right)
$$

for all $n \geq 0$ and $\left\{y_{n}\right\}$ is a Cauchy sequence in $X$.

Now suppose that $A X$ is a complete subspace of $X$. Then there exists $z \in X$ such that

$$
y_{2 n+1}=T\left(x_{2 n+1}\right)=A\left(x_{2 n+2}\right) \rightarrow z
$$

as $n \rightarrow \infty$. Consequently, we can find $w \in X$ such that $A w=z$. Further, a Cauchy sequence $\left\{y_{n}\right\}$ has a convergent subsequence $\left\{y_{2 n+1}\right\}$ and so the sequence $\left\{y_{n}\right\}$ converges and hence a subsequence $\left\{y_{2 n}\right\}$ also converges. Thus we have $y_{2 n}=S\left(x_{2 n}\right)=$ $B\left(x_{2 n+1}\right) \rightarrow z$ as $n \rightarrow \infty$. Letting $x=w$ and $y=z$ in (C2), we get

$$
\begin{aligned}
& {[1+p d(A w, B z)] d(S w, T z)^{2}} \\
& \leq p \cdot \max \left\{\frac{1}{2}\left[d(A w, S w)^{2} d(B z, T z)+d(A w, S w) d(B z, T z)^{2}\right],\right. \\
& \quad d(A w, S w) d(A w, T z) d(B z, S w), d(A w, T z) d(B z, S w) d(B z, T z)\} \\
& \quad+m(A w, B z)-\phi(m(A w, B z)),
\end{aligned}
$$


where

$$
\begin{gathered}
m(A w, B z)=\max \left\{d(A w, B z)^{2}, d(A w, S w) d(B z, T z), d(A w, T z) d(B z, S w),\right. \\
\left.\frac{1}{2}[d(A w, S w) d(A w, T z)+d(B z, S w) d(B z, T z)]\right\} .
\end{gathered}
$$

Since

$$
\begin{gathered}
m(A w, B z)=\max \left\{d(z, z)^{2}, d(z, S w) d(T z, T z), d(z, z) d(z, S w),\right. \\
\left.\frac{1}{2}[d(z, S w) d(z, z)+d(z, S w) d(T z, T z)]\right\}=0, \\
{[1+p d(z, z)] d(S w, z)^{2} \leq p \cdot \max \left\{\frac{1}{2}\left[d(z, S w)^{2} d(z, z)+d(z, S w) d(z, z)^{2}\right],\right.} \\
d(z, S w) d(z, z) d(z, S w), d(z, z) d(z, S w) d(z, z)\}+0-\phi(0) .
\end{gathered}
$$

This implies that $S w=z$ and hence $S w=A w=z$. Therefore, $w$ is a coincidence point of $A$ and $S$. Since $z=S w \in S X \subset B X$, there exists $v \in X$ such that $z=B v$.

Next, we claim that $T v=z$. Now letting $x=x_{2 n}$ and $y=v$ in $(C 2)$, we get

$$
\begin{aligned}
& {\left[1+p d\left(A x_{2 n}, B v\right)\right] d\left(S x_{2} n, T v\right)^{2}} \\
& \leq p \cdot \max \left\{\frac{1}{2}\left[d\left(A x_{2 n}, S x_{2 n}\right)^{2} d(B v, T v)+d\left(A x_{2 n}, S x_{2 n}\right) d(B v, T v)^{2}\right],\right. \\
& \left.\quad d\left(A x_{2 n}, S x_{2 n}\right) d\left(A x_{2 n}, T v\right) d\left(B z, S x_{2 n}\right), d\left(A x_{2 n}, T v\right) d\left(B v, S x_{2 n}\right) d(B v, T v)\right\} \\
& \quad+m\left(A x_{2 n}, B v\right)-\phi\left(m\left(A x_{2 n}, B v\right)\right),
\end{aligned}
$$

where

$$
\begin{gathered}
m\left(A x_{2 n}, B v\right)=\max \left\{d\left(A x_{2 n}, B v\right)^{2}, d\left(A x_{2 n}, S x_{2 n}\right) d(B v, T v), d\left(A x_{2 n}, T v\right) d\left(B v, S x_{2 n}\right),\right. \\
\left.\frac{1}{2}\left[d\left(A x_{2 n}, S x_{2 n}\right) d\left(A x_{2 n}, T v\right)+d\left(B v, S x_{2 n}\right) d(B v, T v)\right]\right\}=0 .
\end{gathered}
$$

Therefore,

$$
[1+p d(z, z)] d(z, T v)^{2} \leq p \cdot \max \left\{\frac{1}{2}[0+0], 0,0\right\}+0-\phi(0) .
$$

This gives $z=T v$ and hence $z=T v=B v$. Therefore, $v$ is a coincidence point of $B$ and $T$. Since the pairs $(A, S)$ and $(B, T)$ are weakly compatible, we have

$$
S z=S(A w)=A(S w)=A z, \quad T z=T(B v)=B(T v)=B z .
$$

Now, we show that $S z=z$. For this, letting $x=z$ and $y=x_{2 n+1}$ in (C2), we get

$$
\begin{aligned}
& {\left[1+p d\left(A z, B x_{2 n+1}\right)\right] d\left(S z, T x_{2 n+1}\right)^{2}} \\
& \leq p \cdot \max \left\{\frac{1}{2}\left[d(A z, S z)^{2} d(z, z)+d(A z, S z) d(z, z)^{2}\right],\right. \\
& \quad d(A z, S z) d(A z, z) d(z, S z), d(A z, z) d(z, S z) d(z, z)\}+m(A z, z)-\phi(m(A z, z)),
\end{aligned}
$$


where

$$
\begin{aligned}
m(A z, z)=\max \{ & d(A z, z)^{2}, d(A z, S z) d(z, z), d(A z, z) d(z, S z), \\
& \left.\frac{1}{2}[d(A z, S z) d(A z, z)+d(z, S z) d(z, z)]\right\}=d(S z, z)^{2} .
\end{aligned}
$$

Therefore, we get

$$
[1+p d(S z, z)] d(S z, z)^{2} \leq p \cdot \max \left\{\frac{1}{2}[0+0], 0,0\right\}+d(S z, z)^{2}-\phi\left(d(S z, z)^{2}\right) .
$$

Thus we get $d(S z, z)^{2}=0$. This implies that $S z=z$. Hence $S z=A z=z$.

Next, we claim that $T z=z$. Now letting $x=x_{2 n}$ and $y=z$ in (C2), we get

$$
\begin{aligned}
& {\left[1+p d\left(A x_{2 n}, B z\right)\right] d\left(S x_{2} n, T z\right)^{2}} \\
& \leq p \cdot \max \left\{\frac{1}{2}\left[d\left(A x_{2 n}, S x_{2 n}\right)^{2} d(B z, T z)+d\left(A x_{2 n}, S x_{2 n}\right) d(B z, T z)^{2}\right],\right. \\
& \left.\quad d\left(A x_{2 n}, S x_{2 n}\right) d\left(A x_{2 n}, T z\right) d\left(B z, S x_{2 n}\right), d\left(A x_{2 n}, T z\right) d\left(B z, S x_{2 n}\right) d(B z, T z)\right\} \\
& \quad+m\left(A x_{2 n}, B z\right)-\phi\left(m\left(A x_{2 n}, B z\right)\right),
\end{aligned}
$$

where

$$
\begin{aligned}
m\left(A x_{2 n}, B z\right)=\max \{ & d\left(A x_{2 n}, B z\right)^{2}, d\left(A x_{2 n}, S x_{2 n}\right) d(B z, T z), d\left(A x_{2 n}, T z\right) d\left(B z, S x_{2 n}\right), \\
& \left.\frac{1}{2}\left[d\left(A x_{2 n}, S x_{2 n}\right) d\left(A x_{2 n}, T z\right)+d\left(B z, S x_{2 n}\right) d(B z, T z)\right]\right\}=d(z, T z)^{2} .
\end{aligned}
$$

Hence we get

$$
[1+p d(z, T z)] d(z, T z)^{2} \leq p \cdot \max \left\{\frac{1}{2}[0+0], 0,0\right\}+d(z, T z)^{2}-\phi\left(d(z, T z)^{2}\right) .
$$

This gives $z=T z$ and hence $z=T z=B z$. Therefore, $z$ is a common fixed point of $A, B, S$ and $T$.

Similarly, we can complete the proofs for the cases that $B X$ or $S X$ or $T X$ is complete.

Now, we prove the uniqueness. Suppose $z$ and $w$ are two common fixed points of $S, T, A$ and $B$ with $z \neq w$. Letting $x=z$ and $y=w$ in (3.2), we get

$$
\begin{aligned}
& {[1+p d(A z, B w)] d(S z, T w)^{2} \leq p \cdot \max \{0,0,0\}+m(A z, B w)-\phi(m(A z, B w)),} \\
& {[1+p d(A z, B w)] d(S z, T w)^{2} \leq p \cdot \max \{0,0,0\}+d(S z, T w)^{2}-\phi\left(d(S z, T w)^{2}\right),}
\end{aligned}
$$

which implies that $d(z, w)^{2}=0$. Hence $z=w$. This completes the proof.

Theorem 2. If a 'weakly compatible' property in the statement of Theorem 1 is replaced by one (retaining the rest of hypotheses) of the following:

(i) R-weakly commuting property;

(ii) $R$-weakly commuting mappings of type $\left(A_{f}\right)$;

(iii) $R$-weakly commuting mappings of type $\left(A_{g}\right)$;

(iv) $R$-weakly commuting mappings of type $(P)$; 
(v) weakly commuting,

then Theorem 1 remains true.

Proof. Since all the conditions of Theorem 1 are satisfied, the existence of coincidence points for both the pairs is insured. Let $w$ be an arbitrary point of coincidence for the pair $(A, S)$. Then using $R$-weak commutativity, one gets

$$
d(A S w, S A w) \leq R d(A w, S w),
$$

which implies $A S w=S A w$. Thus the pair $(A, S)$ is coincidentally commuting. Similarly, $(B, T)$ commutes at all of its coincidence points. Now applying Theorem 1, one concludes that $S, T, A$ and $B$ have a unique common fixed point.

If $(A, S)$ are $R$-weakly commuting mappings of type $\left(A_{f}\right)$, then

$$
d(A S w, S S w) \leq R d(A w, S w),
$$

which implies that $A S w=S S w$. Since

$$
d(A S w, S A w) \leq d(A S w, S S w)+d(S S w, S A w)=0+0=0,
$$

which implies that $A S w=S A w$.

Similarly, if $(A, S)$ are $R$-weakly commuting mappings of type $\left(A_{g}\right)$ or of type $(P)$ or weakly commuting, then $(A, S)$ also commute at their points of coincidence.

Similarly, one can show that the pair $(B, T)$ is also coincidentally commuting. Now in view of Theorem 1, for all four cases, $A, B, S$ and $T$ have a unique common fixed point. This completes the proof.

As an application of Theorem 1, we prove a common fixed point theorem for four finite families of mappings.

Theorem 3. Let $\left\{A_{1}, A_{2}, \cdots, A_{m}\right\}, \quad\left\{B_{1}, B_{2}, \cdots, B_{n}\right\}, \quad\left\{S_{1}, S_{2}, \cdots, S_{p}\right\}$ and $\left\{T_{1}, T_{2}, \cdots, T_{q}\right\}$ be four finite families of self-mappings of a metric space $(X, d)$ such that $A=A_{1} A_{2} \cdots A_{m}, B=B_{1} B_{2} \cdots B_{n}, S=S_{1} S_{2} \cdots S_{p}$ and $T=T_{1} T_{2} \cdots T_{q}$ satisfy the conditions (C1), (C2) and one of the mappings $A(X), B(X), S(X)$ and $T(X)$ is a complete subspace of $X$. Then

(i) A and $S$ have a point of coincidence,

(ii) $B$ and $T$ have a point of coincidence.

Moreover, if $A_{i} A_{j}=A_{j} A_{i}, B_{k} B_{l}=B_{l} B_{k}, S_{r} S_{s}=S_{s} S_{r}, T_{t} T_{u}=T_{u} T_{t}, A_{i} S_{r}=S_{r} A_{i}$ and $B_{k} T_{t}=T_{t} B_{k}$ for all $i, j \in I_{1}=\{1,2, \cdots, m\}, k, l \in I_{2}=\{1,2, \cdots, n\}, r, s \in I_{3}=$ $\{1,2, \cdots, p\}$ and $t, u \in I_{4}=\{1,2, \cdots, q\}$, then (for all $i \in I_{1}, k \in I_{2}, r \in I_{3}$ and $t \in I_{4}$ ) $A_{i}, S_{r}, B_{k}$ and $T_{t}$ have a common fixed point.

Proof. The conclusions (i) and (ii) are immediate since $A, S, B$ and $T$ satisfy all the conditions of Theorem 1 . Now appealing to component wise commutativity of various pairs, one can immediately prove that $A S=S A$ and $B T=T B$ and hence, obviously, both pairs $(A, S)$ and $(B, T)$ are weakly compatible. Note that all the conditions of Theorem 1 (for mappings $A, S, B$ and $T$ ) are satisfied to ensure the existence of a 
unique common fixed point, say, $z$. Now one needs to show that $z$ remains the fixed point of all the component mappings. For this, consider

$$
\begin{aligned}
S\left(S_{r} z\right) & =\left(\left(S_{1} S_{2} \cdots S_{p}\right) S_{r}\right) z=\left(S_{1} S_{2} \cdots S_{p-1}\right)\left(\left(S_{p} S_{r}\right) z\right) \\
& =\left(S_{1} S_{2} \cdots S_{p-1}\right)\left(S_{r} S_{p} z\right)=\left(S_{1} S_{2} \cdots S_{p-2}\right)\left(S_{p-1} S_{r}\left(S_{p} z\right)\right) \\
& =\left(S_{1} S_{2} \cdots S_{p-2}\right)\left(S_{r} S_{p-1}\left(S_{p} z\right)\right)=\cdots \\
& =S_{1} S_{r}\left(S_{2} S_{3} S_{4} \cdots S_{p} z\right)=S_{r} S_{1}\left(S_{2} S_{3} \cdots S_{p} z\right)=S_{r}(S z)=S_{r} z .
\end{aligned}
$$

Similarly, one can show that

$$
\begin{aligned}
A\left(S_{r} z\right) & =S_{r}(A z)=S_{r} z, A\left(A_{i} z\right)=A_{i}(A z)=A_{i} z, \\
S\left(A_{i} z\right) & =A_{i}(S z)=A_{i} z, B\left(B_{k} z\right)=B_{k}(B z)=B_{k} z, \\
B\left(T_{t} z\right) & =T_{t}(B z)=T_{t} z, T\left(T_{t} z\right)=T_{t}(T z)=T_{t} z, \\
T\left(B_{k} z\right) & =B_{k}(T z)=B_{k} z,
\end{aligned}
$$

which implies that (for all $i, r, k$ and $t$ ) $A_{i} z$ and $S_{r} z$ are other fixed points of the pair $(A, S)$, whereas $B_{k} z$ and $T_{t} z$ are other fixed points of the pair $(B, T)$.

Now appealing to the uniqueness of common fixed points of both pairs, separately, we get

$$
z=A_{i} z=S_{r} z=B_{k} z=T_{t} z
$$

which shows that $z$ is a common fixed point of $A_{i}, S_{r}, B_{k}$ and $T_{t}$ for all $i, r, k$ and $t$.

Setting $A=A_{1}=A_{2}=\cdots=A_{m}, B=B_{1}=B_{2}=\cdots=B_{n}, S=S_{1}=S_{2}=\cdots=S_{p}$ and $T=T_{1}=T_{2}=\cdots=T_{q}$, one can deduce the following result for certain iterates of mappings.

Corollary 1. Let $A, B, S$ and $T$ be four self-mappings of a metric space $(X, d)$ such that $A_{m}, B_{n}, S_{p}$ and $T_{q}$ satisfy the conditions $(C 1)$ and $(C 2)$. If one of the mappings $A_{m}(X), B_{n}(X), S_{p}(X)$ and $T_{q}(X)$ is a complete subspace of $X$, then $A, B, S$ and $T$ have a unique common fixed point provided $(A, S)$ and $(B, T)$ commute.

Theorem 4. Let $S, T, A, B$ be four mappings of a complete metric space $(X, d)$ into itself satisfying all the conditions of Theorem 1 except $(C 2)$, where $(C 2)$ is replaced by $(C 3)$

$$
\int_{0}^{M(x, y)} \gamma(t) d t \leq p \int_{0}^{N(x, y)} \gamma(t) d t
$$

Here

$$
\begin{gathered}
M(x, y)=(1+p d(A x, B y)) d(S x, T y)^{2} \\
N(x, y)=\max \left\{\frac{1}{2}\left(d(A x, S x)^{2} d(B y, T y)+d(A x, S x) d(B y, T y)^{2}\right)\right. \\
d(A x, S x) d(A x, T y) d(B y, S x), d(A x, T y) d(B y, S x) d(B y, T y)\} \\
+m(A x, B y)-\phi(m(A x, B y)),
\end{gathered}
$$


$p \geq 0$ is a real number, $\phi:[0, \infty) \rightarrow[0, \infty)$ is a continuous function with $\phi(t)=0$ if and only if $t=0$ and $\phi(t)>t$ for all $t>0$ and $\gamma:[0, \infty) \rightarrow[0, \infty)$ is a Lebesgue integrable function which is summable on each compact subset of $[0, \infty)$ such that for each $\varepsilon>0, \int_{0}^{\varepsilon} \gamma(t) d t>0$. Then $S, T, A, B$ have a unique common fixed point.

Proof. Letting $\gamma(t)=c$ in Theorem 1, we obtain the required results.

Example 2. Let $X=[2,20]$ and $d$ be a usual metric. Define self-mappings $A, B, S$ and $T$ on $X$ by

$$
\begin{gathered}
A x=\left\{\begin{array}{ll}
12 & \text { if } 2<x \leq 5 \\
x-3 & \text { if } x>5 \\
2 & \text { if } x=2,
\end{array} \quad B x= \begin{cases}2 & \text { if } x=2 \\
6 & \text { if } x>2,\end{cases} \right. \\
S x=\left\{\begin{array}{ll}
6 & \text { if } 2<x \leq 5 \\
x & \text { if } x=2 \\
2 & \text { if } x>5,
\end{array} \quad T x= \begin{cases}x & \text { if } x=2 \\
3 & \text { if } x>2 .\end{cases} \right.
\end{gathered}
$$

Let us consider a sequence $\left\{x_{n}\right\}$ with $x_{n}=2$. It is easy to verify that all the conditions of Theorem 1 are satisfied. In fact, 2 is the unique common fixed point of $S, T, A$ and $B$.

\section{CONCLUSION}

In this paper, we have proved a common fixed point theorem for pairs of weakly compatible mappings satisfying a generalized $\phi$-weak contraction condition that involves cubic terms of metric functions. Next, we have proved some results using different variants of $R$-weakly commuting mappings. Finally, we have given an application in support of our results.

\section{COMPETING INTERESTS}

The authors declare that they have no competing interests.

\section{REFERENCES}

[1] O. Acar, "A fixed point theorem for multivalued almost $F$ - $\delta$-contraction," Results Math., vol. 2, no. 3, pp. 1545-1553, 2017, doi: 10.1007/s00025-017-0705-5.

[2] Y. I. Alber and S. Guerre-Delabriere, "Principle of weakly contractive maps in Hilbert spaces," New Results Operator Theory Adv. Appl. , vol. 98, no. 1, pp. 7-22, 1997, doi: 10.1137/050641867.

[3] B. Boonsri and S. Saejung, "Fixed point theorems for contractions of Reich type on a metric space with a graph," J. Fixed Point Theory Appl., vol. 20, no. 2, pp. 1-17, 2018, doi: 10.1007/s11784018-0565-y.

[4] D. W. Boyd and J. S. W. Wong, "On nonlinear contractions," Proc. Am. Math. Soc., vol. 20, no. 2, pp. 458-464, 1969.

[5] M. Imdad and J. Ali, "Some common fixed point theorems in fuzzy metric spaces," Math. Commun., vol. 11, no. 2, pp. 153-163, 2006. 
[6] D. Jain, S. Kumar, S. Kang, and C. Jung, "Weak contraction condition for compatible mappings involving cubic terms of the metric function," Far Esat J. Math. Sci., vol. 103, no. 4, pp. 799-818, 2018, doi: 10.17654/MS103040799.

[7] G. Jiang and S. Kang, "Common fixed point theorems with an application in dynamic programming," Miskolc Math. Notes, vol. 19, no. 2, pp. 923-930, 2018, doi: 10.18514/MMN.2018.2312.

[8] G. Jungck, "Commuting mappings and fixed points," Am. Math. Monthly, vol. 83, pp. 261-263, 1976.

[9] G. Jungck and B. E. Rhoades, "Fixed points for set valued functions without continuity," Indian J. Pure Appl. Math., vol. 29, no. 3, pp. 227-238, 1998.

[10] S. Kajántó and A. Lukács, "On the conditions of fixed-point theorems concerning $F$-contractions," Results Math., vol. 73, no. 2, pp. 1-10, 2018, doi: 10.1007/s00025-018-0846-1.

[11] K. Kim, "Convergence and stability of generalized $\varphi$-weak contraction mapping in $C A T(0)$ spaces," Open Math., vol. 15, no. 1, pp. 1063-1074, 2017, doi: 10.1515/math-2017-0089.

[12] S. Kumar and S. K. Garg, "Expansion mapping theorems in metric spaces," Int. J. Contemp. Math. Sci., vol. 4, no. 36, pp. 1749-1758, 2009.

[13] R. P. Pant, "Common fixed point for non commuting mappings," J. Math. Anal. Appl., vol. 188, no. 2, pp. 436-440, 1994.

[14] H. K. Pathak, Y. Cho, and S. Kang, "Remarks on $R$-weakly commuting mappings and common fixed point theorems," Bull. Korean Math. Soc., vol. 34, no. 2, pp. 247-257, 1997.

[15] B. E. Rhoades, "Some theorems on weakly contractive maps. Proceedings of the Third World Congress of Nonlinear Analysis, Part 4 (Catania, 2000)," Nolinear Anal., vol. 47, no. 4, pp. 2683 2693, 2001, doi: /10.1016/S0362-546X(01)00388-1.

[16] S. Sessa, "On a weak commutativity conditions of mappings in fixed point consideration," Publ. Inst. Math. (Beograd), vol. 32, pp. 146-153, 1982.

\section{Authors' addresses}

Deepak Jain

Deepak Jain, Department of Mathematics, Deenbandhu Chhotu Ram University of Science and Technology, Murthal, Sonepat 131039, Haryana, India

E-mail address: deepakjain.jain6@gmail.com

\section{Sanjay Kumar}

Sanjay Kumar, Department of Mathematics, Deenbandhu Chhotu Ram University of Science and Technology, Murthal, Sonepat 131039, Haryana, India

E-mail address: sanjaymudgal2004@yahoo.com

Choonkil Park

Choonkil Park, Hanyang University, Department of Department, Research Institute for Natural Sciences, Seoul 04763, Korea

E-mail address: baak@hanyang.ac.kr 